\title{
Remote Sensing and Geographic Information Techniques: Veritable Tools for Land Degradation Assessment
}

\author{
Idowu Innocent Abbas ${ }^{1}$, Mayowa Johnson Fasona ${ }^{2, *}$ \\ ${ }^{1}$ Department of Geography, Ahmadu Bello University, Zaria, 810001, Nigeria \\ ${ }^{2}$ Department of Geography, University of Lagos, Lagos, Nigeria
}

\begin{abstract}
Land degradation can be defined as land which due to natural processes or human activity is no longer able to sustain properly its economic function and/or its original natural ecological function. The implications of the land use-land cover change often lead to land degradation. This study used Landsat TM image of 1986 and Nigeriasat-1 image of 2008 to assess the degraded lands for the respective years in a section of Niger Delta, Nigeria. The data sets were analysed using Arcview software in the Geographic Information System environment. The results show the different types of land degradation, the area coverage of the degraded lands for the years and how the people of the study area were affected. Based on the findings, recommendations are made to stem and eventually curtail the degradation.
\end{abstract}

Keywords Degradation, Remote Sensing, Geographic Information System, Satellites, Implications

\section{Introduction}

\subsection{Overview}

The task of managing natural resources of the earth is daily growing in complexities. This is due partly to increasing uncertainties in the natural-physical systems, as well as increasing interference of man with these systems. Natural resources development and management is of tremendous concern to man's kind. The utility derivable from resource use and the deleterious effects and consequences of resource abuse are important for continued existence of man and survival of the natural ecosystems.

Degradation sets in when the capacity of a natural ecosystem to renew itself is constrained by frequent disturbance and/or perturbations and this is a big threaten to human survival and livelihoods[1].[2] indicates that land degradation is a reduction in the resource potential of a land through the actions or processes that may force the conditions of the land to become unpleasant and less useful to man. Such processes include water erosion, wind erosion, flood hazard, drought and desertification, devegetation, salinization, alkalization, loss of fertility, long term reduction in diversity of natural vegetation, reservoir sedimentation, toxicity hazards, moisture stress, pollution, saline intrusion, subsidence, and permanent inundation of land among others.

Maps and measurements of degraded land can be derived directly from remotely sensed data by a variety of analytical

* Corresponding author:

olamideolumide@yahoo.com (Mayowa Johnson Fasona)

Published online at http://journal.sapub.org/ajgis

Copyright (C) 2012 Scientific \& Academic Publishing. All Rights Reserved procedures, including statistical methods and human interpretation[3]. Conventional maps are categorical, dividing land into categories of land use and land cover (thematic mapping; land classification), while recent techniques allow the mapping of land degradation and other properties of land as continuous variables or as fraction of the land by different land use-land cover categories, such as tree canopy, herbaceous vegetation, and barren (continuous fields mapping). These types of datasets may be compared between time periods using Geographic Information Systems (GIS) to map and measure their extent and change at local, regional, and global scales[4]. Assessing and mapping land degradation through the old traditional method of field surveying can be tedious and time consuming. However, with the introduction of Remote Sensing and Geographic Information System technologies, mapping land degradation becomes easy, less time consuming and gives room for regular updating and projection with a view to effectively and efficiently manage land resources[5].

The study area which is called the Transgressive Mahin mud coastal area (western Niger Delta) lies approximately between longitudes $4^{0} 30^{1}$ and $5^{0} 07^{1}$ East of the Greenwich and latitudes $5^{0} 45^{1}$ and $6^{\circ} 30^{1}$ north of the Equator. It extends westwards from the mouth of the Benin River to the approach of Mahin mud-beach coast. It covers an area of about $3,310 \mathrm{~km}^{2}$, a mud coastline distance of $88 \mathrm{~km}$ and an inland distance of $50 \mathrm{~km}$ and $19 \mathrm{~km}$ respectively at its farthest and closest stretches from the Atlantic coastline. The area covers principally communities in Ilaje and Ese-Odo local government areas of Ondo state. It also extends to small parts of Ikale (Okitipupa) and Irele local government areas in Ondo state[6]. 


\subsection{Objectives}

Land degradation is widespread in the study area as reported by several scholars such as[7, 8]; and[9] however there has been no up to date quantitative documentation of the degraded lands. This research therefore looks at land degradation in the Transgressive Mahin mud coast (western Niger Delta) between 1986 and 2008. The area coverage of the degraded lands and the implications on the people of the study area are hereby examined with a view to making recommendations on how to combat or minimize the degradation. This study is therefore to assess and document the nature of land degradation that is going on in the study area. It is also primarily intended that this study will further demonstrate the usefulness of the techniques of Remote Sensing and GIS in land degradation assessment in the study area.

\section{Materials and Methods}

The Landsat TM imagery of 1986 from[10] was used to generate the degraded lands in 1986. The Landsat Thematic Mapper (TM) has 7 spectral bands with spatial resolution of $30 \mathrm{~m}$ on all the bands except the thermal infrared (TIR) band with $60 \mathrm{~m}$ (table 1). The Nigeriasat-1 imagery of 2008 was acquired from National Space Research and Development Agency (NASRDA), Abuja and it was used to generate the degraded lands in 2008. It has 3 spectral bands with spatial resolution of $32 \mathrm{~m}$ on all the bands (table 2).

The imageries were georectified to UTM-31 projection, WGS84 datum and corrected for geometric and radiometric errors from the sources. Inspection of dates of acquisition shows that the two imageries (Landsat TM and Nigeriasat-1) were acquired in dry season. Stacking of the image bands to generate a composite image was carried out using Arcview GIS software. For both the Landsat TM imagery and Nigeriasat-1 imagery the band combination 1, 4, and 7 (blue, red, near infrared) gave the best combination for visually interpreting vegetation and other land cover classes.

Table 1. Spectral Bands of Landsat Tm

\begin{tabular}{|c|c|c|}
\hline Band & Name & Band wavelengths \\
\hline Band 1 & Blue & $0.45-0.52$ \\
Band 2 & Green & $0.52-0.60$ \\
Band 3 & Red & $0.63-0.69$ \\
Band 4 & Near infrared & $0.76-0.90$ \\
Band 5 & Mid infrared & $1.55-1.75$ \\
Band 6 & Thermal infrared & $10.40-12.50$ \\
Band 7 & Far infrared & $2.08-2.35$ \\
\hline
\end{tabular}

Table 2. Spectral Bands of Nigeriasat-1

\begin{tabular}{|c|c|c|}
\hline Band & Name & Band wavelengths \\
\hline Band 1 & Green & $0.52-0.6$ \\
Band 2 & Red & $0.63-0.69$ \\
Band 3 & Near Infrared (NIR) & $0.76-0.90$ \\
\hline
\end{tabular}

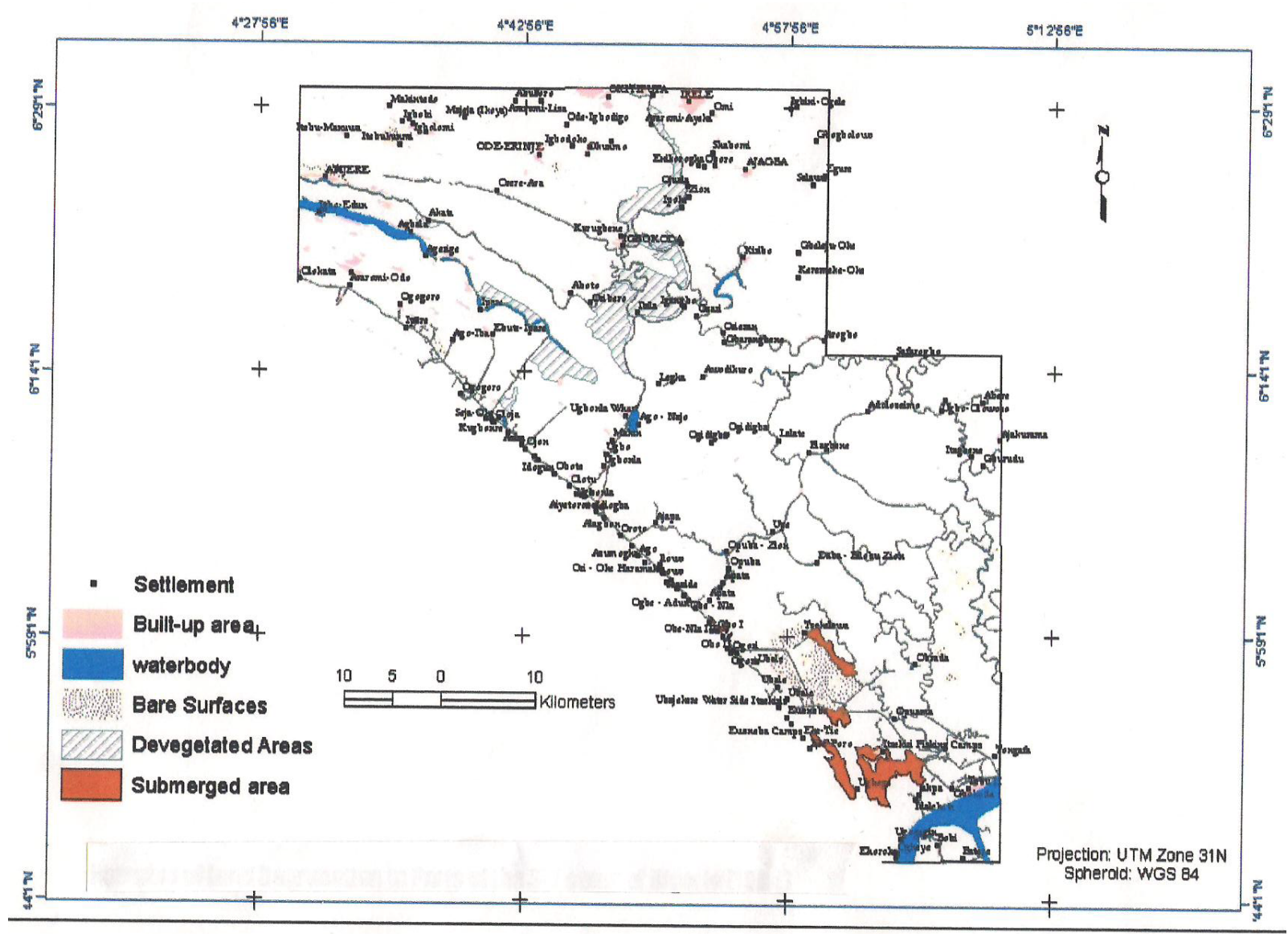

Figure 1. The degraded lands in 1986 


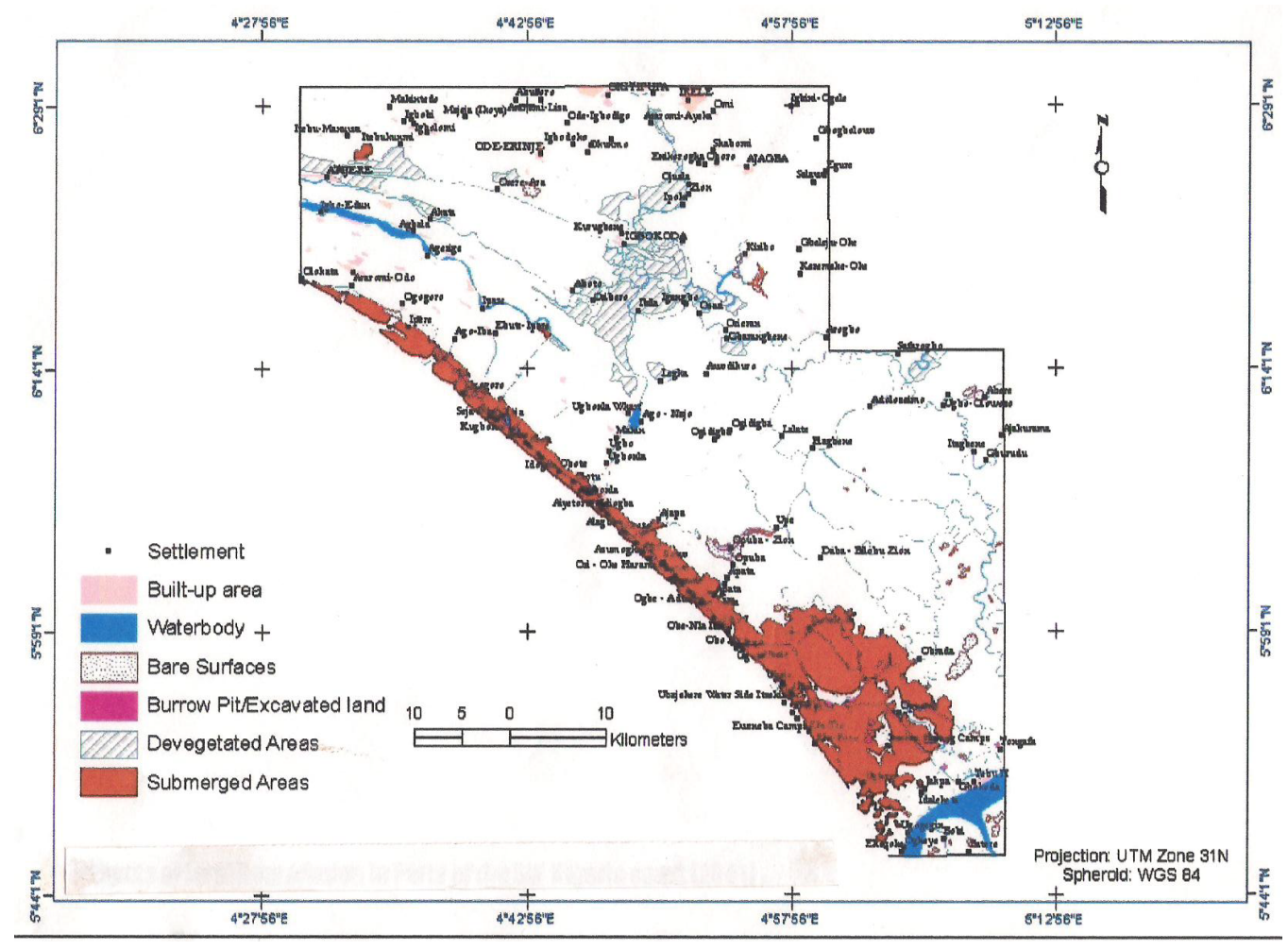

Figure 2. The degraded lands in 2008

The process of vector layers extraction from the images was done using the head-up (on-screen) digitizing method. This involved creating an empty theme of desired feature representation (point, line or polygon) within the view interface of Arcview GIS. Using the drawing and editing tools of the software, each entity of the feature of interest was traced out. The predefined code for each entity was attached as attribute. A look-up-table (LUT) was then prepared to assign all the entities into respective feature classes as appropriate.

Field check was conducted to verify the accuracy of the Nigeriasat-1 image data. The field check was conducted with a handheld Garmin S76 Global Positioning Systems (GPS), digital camera and field note. The coordinates of some selected features were taken on the field and were used to verify those on the imagery using[11] method and the reliability was $88.1 \%$.

\section{Results and Discussion}

The extent and the different percentages of the area mapped as degraded lands in 1986 and 2008 are shown in table 3. The maps of the degraded lands in 1986 and 2008 are also shown in figures 1 and 2 respectively.

From table 3, it can be observed that degraded lands accounts for $10.6 \%$ in 1986 and $32.16 \%$ in 2008 . From the GIS analysis, dredged river/canal and scrub/grassland decreased in area from $0.6 \%$ and $3.4 \%$ in 1986 to $0.59 \%$ and $2.44 \%$ in 2008 respectively. Submerged (permanently inundated) lands and bare surfaces (encompassing eroded/out washed areas, saline intrusion impacted surfaces and sterile uplands glass and surfaces) experienced remarkable respective increase from $1.2 \%$ and $1.7 \%$ in 1986 to $12.35 \%$ and $10.65 \%$ in 2008. Devegetated areas (including logging area and cleared forest) increased form $3.7 \%$ in 1986 to $5.3 \%$ in 2008 . Emerging degraded classes in 2008 include burrowed pit/ excavated lands $(0.16 \%)$, accumulated mud $(0.01 \%)$ and dredged spoil $(0.06 \%)$.

Table 3. Coverage of Degraded Lands of the Study Area in Percentage

\begin{tabular}{|c|c|c|c|c|}
\hline \multirow{2}{*}{$\mathrm{S} / \mathrm{N}$} & \multirow{2}{*}{ Degraded Lands } & \multicolumn{3}{|c|}{ Percent of Degraded Lands use } \\
\cline { 3 - 5 } & & 2008 & 1986 & \\
\hline 1 & Dredged river/canal & 0.59 & 0.60 & \\
\hline 2. & Submerged areas & 12.35 & 1.20 & \\
\hline 3. & Burrow pit/excavated land & 0.16 & -- & \\
\hline 4. & Bare surfaces & 10.65 & 1.70 & \\
\hline 5 & Devegetated areas & 5.30 & 3.70 & \\
\hline 6. & Scrub/grassland & 2.44 & 3.40 & \\
\hline 7 & Dredged spoil & 0.06 & --- & \\
\hline 8 & Mud & 0.01 & --- & \\
\hline & Total & 32.16 & 10.60 & \\
\hline
\end{tabular}

\section{Discussion}

\subsection{Scrub/Coastal Grassland}

Scrub/coastal grassland represent impacts of pressure on existing land cover classes such as heavy forest, light forest/thicket, farmland/fallow, palm swamp, thickets and even mangrove ecology. Scrub/coastal grassland is therefore not a native natural class, but an indicator of disturbance or consistent perturbations created by pressure on existing ecologies. It also indicates progressive loss of power of regeneration and ability of affected ecology to return to climax. 
Persistent disturbance through logging, bush clearing and bush fire have stretched the resilience to the limits. Consistent perturbation reduces the land functions through loss of soil nutrient, decline of biogeochemical activities and eventual loss of agricultural land which by implication is loss of livelihood[12]. When the rate of perturbation exceeds the power of natural regeneration, natural forests give way to grassland. Scrub and coastal grassland emerged from the 1986 mapping

\subsection{Submerged Area}

Being a region of strong horizontal heterogeneity, the interface between land, sea and air, the local climatic conditions are complex, while the global climatic influences are enormous. Such effects of climate change manifest in eustatic sea level rise, which can be compounded by local land subsidence. Thus the region is particularly sensitive and susceptible to alteration in sea level. Submerged areas represent permanently inundated lands. This degraded class might have resulted from lowering of the land below the sea level due to subsidence. It could also be as a result of increased climate change causing the rise in the sea level hence making the ocean water to rise into the land. From observation, these permanently inundated lands are localized around the coastal fringes and around the rivers and creeks.

This is because these areas were originally tidal flats separated from the ocean by extensive marshland and mangrove. The canalization of some small streams from the land to the sea actually opened the land area to constant and consistent saline water inflow from the ocean. The process destroyed the marsh and mangrove ecosystems that served as buffer from the ocean. Submerged lands have permanently lost the ability for natural regeneration.

Saline water inflow and permanent inundation are externalities resulting from oil exploration activities. Saline water inflow into land area is a result of canalization and some of these canals were constructed to route or connect offshore and on-shore pipelines to flow-stations. Marsh, palm swamp, lake/pond and built up areas, heavy and light forests and mangrove have been destroyed by saline water inflow into the land area. In summary, submerged area emerged with area coverage of $1.2 \%$ in 1986 , and expanded to $12.35 \%$ area coverage in 2008.

The effects of saline water inundation include forced relocation of settlements, loss of livelihoods especially the inundation of small lakes and ponds that are breeding ground for varieties of fishes and other aquatic fauna that served as means of livelihood to majority of the inhabitants. Loss of aquatic habitats for native flora may also have occurred. More importantly, permanent inundation of some lands has rendered them unpleasant and unproductive especially for agriculture and living. Communities such as Ori Oke Iwamimo, Ijo-Odo, Oloja, Magbewa, Asisa, Yaye, Olotu, Ugbonla, Aiyetoro, Idiogba, Alagbon, Mesade, Ilepete, Obe Nla, Ogba Adun, Obe Nla III, Obo, Molume, Awoye and Eketie are already seriously impacted. New built up area mapped in 1986 and 2008 are likely evidences to suggest that some of these settlements may have moved from their original location in the past as a result of submergence.

\subsection{Dredged River/Canal}

Dredged river and canals as a result of multinational oil companies were made due to oil exploration to facilitate transportation to gain access to the inland areas from the sea and to improve access between the coastal and upland communities. Some canals were constructed as well slots to situate oil well heads while some were also constructed to connect onshore and offshore well heads to flow-stations and tank-farms, and also to route long distance oil bearing pipelines.

The area mapped as canals covered $0.6 \%$ of the total area in 1986 and $0.59 \%$ in 2008 . Some lake/ponds were lost to the emergence of dredged canal. Negative impacts of these canals that came with oil exploration are clear in the opening of land to saline water inundation. Four canals in 1986 which increased to 9 in 2008 opened the land area into the Atlantic. This is to show that the decimation of marsh and mangrove lands and permanent inundation of some areas are results of saline water inflow into land areas through these canals.

\subsection{Bare Surfaces}

Bare surfaces are areas that have been exposed. They include white (glass) sands, areas that had experienced saline water intrusion as well as eroded/out-washed surfaces. Bare surfaces are devoid of vegetation and are therefore not productive. It occurred due to long and sustained ecological process breakdown that led to ecology loss. Bared surface had $1.7 \%$ total area coverage in 1986 but increased tremendously to $5.3 \%$ in 2008 . Light forest/thicket, heavy forest and palm swamp were the major contributors to its growth in 2008. The contributions of the forests and palm swamps probably result from unsustainable logging and opening-up of lands. Eroded surfaces are found on sea shore and where it is intense, settlements have been uprooted.

\subsection{Devegetated Areas}

Devegetated areas are areas of intensive logging activities. These include area $\mathrm{s}$ of harvested teak, gmelina, and old rubber plantations. Devegetated areas also include forested areas that are newly cleared for farming and areas where mangrove forests and marshlands have been harvested (mainly for fuel wood). Devegetated areas which are localized around the upland areas are bare of vegetation. Light forest/thicket, mangrove and marshland contributed to Devegetated areas in 1986 with area coverage of $3.7 \%$. The extent increased to $5.3 \%$ in 2008 with contributions from farmland/fallow land palm swamp and heavy forests. Evidence of devegetation also abounds in the numerous logs floating on the rivers especially around the upland areas.

\subsection{Burrow Pit/Excavated Lands}

Burrow pit/excavated land is mainly an offshoot of oil activities though sand excavation is done also for building purposes, mining for sale and road construction. Burrow pit 
and excavated lands are spots excavated in anticipation for oil drilling. In other cases these spots were excavated to collect sands during construction of infrastructures including flow stations and roads. $0.06 \%$ of the study area was mapped as burrow pit/excavated land in 2008 .

\subsection{Mud and Dredge Spoil}

Mud is a natural beach and river deposits of the areas around the Transgressive Mahin mud coast. It is so named because of this singular characteristic. Dredged spoil represents deposits or debris removed during canalization of lands and dredging of streams. Where both mud and dredge spoil are found, the land is technically sterile. Both mud and dredge spoil form a compaction on the top soil which prevents the growth of vegetation. Mud covered $0.01 \%$ of the total study area in 2008 while the dredged spoil had area coverage of $0.06 \%$ mapped in 2008 .

\subsection{Implications of Land Degradation}

Poor communities where livelihoods are completely tied to the land suffer more from land degradation, which make them more vulnerable to hazards $[13 ; 14 ; 8]$.

Therefore, land degradation and disruptions do not only constitute a hazard because of direct impact on livelihoods of communities which may lead to starvation and loss of human lives, but can also facilitate the occurrence of other continuous but slow evolving disasters processes. At the same time it increases disaster vulnerability by exposing human lives and economic and social assets to the risk of other geotectonic, oceanic, climatic and hydro-meteorological hazards such as flooding, erosion, storm surges, subsidence, etc.

The implications of land degradation are enormous on the study area especially as it concerns livelihood of the people. Lakes and ponds in the study area serve as breeding grounds for fish and other aquaculture resources which is the backbone of the local economy. About $82 \%$ of the population in the study area takes farming especially fishing as either major or minor occupation[5]. In essence, numerous small communities and fishing villages whose livelihoods depend on local fishing would be vulnerable especially with limited diversification of means of livelihood as a result of disappearance/degradation of the lakes and pond. Some communities formerly located near these lakes and ponds have since relocated because they were no longer there to support them. This means that the local economy has been impacted to some extent which is exacerbating the poverty level in the study area.

A large proportion of critically vulnerable settlements in the study area are first-line settlements located within or close to the sea. They are also areas where the livelihoods of communities are seriously impacted and poverty is high. These are rural communities where neither structural (dykes, levees, refuge platforms) nor non-structural (land use planning, education, government policies, and micro insurance) responses are in place. The fact on ground is that there are no available detailed data and information with the government about the precarious state of these communities. The implication is that nothing would probably be done and their existence and state may only be known when the continuous land degradation eventually leads to unrest or even arm struggle. This may translate to massive impacts on these communities which by then may have lost everything including trust on the government.

\section{REFERENCES}

[1] Abbas, I I (2009): "Use of Satellite Remote Sensing and Geographic Information Systems to Monitor Land Degradation along Ondo Coastal Zone, Nigeria" Journal of Geography and Environmental Planning, Vol.5 No.1 March, 2009 pp 26-35

[2] Abdukadir, A. (1993): Remote Sensing and Land Degradation. Nigerian Journal of Remote Sensing, Vol. 1(1), pp 65-72

[3] Benedine, A; Robert, T.A and Abbas, I.I (2011): The Impact of Spatial distribution of solid waste dumps on infrastructure in Samaru, Zaria, Nigeria using GIS, Research Journal of Information Technology, Vol. 3(3); pp 113-117, 2011

[4] Abbas,I.I and Arigbede, Y.A (2011): Sustainable Land Management in Zaria using Remote Sensing and GIS techniques, Journal of Ecology and the Natural Environment 3(4): pp 131-138, April, 2011

[5] Abbas, I.I; Muazu, K.M and Ukoje, J.A (2010): Mapping Land use- land cover and Change Detection in Kafur Local Government, Katsina, Nigeria (1995-2008) using Remote Sensing and GIS. Research Journal of Environmental and Earth Sciences, 2010 Vol.2.Issue 1, pp 6- 12

[6] OSOPADEC (2009): A Compedium of the Commission's Formation and Activities, Ondo State Oil Producing Area Development Commission, Integrity Press Ltd, Akure.

[7] Fasona, M.J (2007): Land Degradation and Environmental Change in Ondo State, South-West, Nigeria, An (unpl) PhD thesis, University of Lagos

[8] McBean, G.A (2006): Hazards and Disasters- a Research Challenge. Paper Presented at the Regional Conference on Natural and Human-Induced Environmental Hazards and Disasters hosted by ICSU Regional office for Asia-Pacific, Kuala Lumpur, Malaysia, 18-19 September, 2006, www.icsu-asia-pa Mid Atlantic Regional Earth Science Application Center (RESAC). Landscape Metrics Used to Assess Anthropogenic Influence on Wetland Anacostia Watershed. www.geou.uind.ediWresac/aivicosl.htm

[9] Fabiyi, O (2008): Mapping Environmental Sensitivity Index of the Niger Delta to Oil Spill; the policy, procedures and politics of Oil spill response in Nigeria Proceedings of Map Africa 2008 Conference, Johannesburg, South Africa, August $21-22$

[10] www.glcf.umiacs.umd.edu

[11] Jensen, J R (1986): Introductory Digital Image Processing A remote Sensing perspective, Prentice-Hall, N.J, 379p 
[12] Mayowa, J F; Omojola, A and Soneye, A (2009): Adapting land use to climate change on the coast of Ondo state, southwest Nigeria, IOP Conference Series: Earth and Environmental Science Volume 6 Session 34
[13] Ojo, S.O (1987): The Climatic Drama, Inaugural lecture Series, University of Lagos Press

[14] UNEP - GRID-Arendal (2005): Environment Times No 3, GRID-Arendal, Logum Park, Service Box 706, Arendal 